\title{
Moisture-Dependent Physical Properties of Sunflower Seed (SHF8190)
}

\author{
Mohammad Reza Seifi (Corresponding author) \\ Department of Agricultural Machinery Engineering, Faculty of Agricultural Engineering and Technology \\ College of Agricultural and Natural Resources, University of Tehran \\ P.O. Box 4111, Karaj 31587-77871, Iran \\ Tel: 98-936-673-0986_E-mail: mrseifi83@yahoo.com
}

Reza Alimardani

Department of Agricultural Machinery Engineering, Faculty of Agricultural Engineering and Technology

College of Agricultural and Natural Resources, University of Tehran

P.O. Box 4111, Karaj 31587-77871, Iran

The research is financed by Faculty of Agricultural Engineering \& Technology, University of Tehran, Karaj, Iran.

\begin{abstract}
Physical properties are very important in design and manufacturing of harvest and post harvest machines. In this research some physical properties of sunflower seeds (SHF8190 variety) were determined as a function of moisture content in the range of 4-22\% wet basis (w.b.) using standard techniques. The average length, width, thickness, geometric mean diameter, equivalent diameter, arithmetic diameter, sphericity, surface area and angle of repose ranged from 12.14 to $12.57 \mathrm{~mm}, 5.79$ to $6.38 \mathrm{~mm}, 3.86$ to $4.09 \mathrm{~mm}, 6.47$ to $6.85 \mathrm{~mm}, 6.56$ to $6.97 \mathrm{~mm}$, 7.27 to $7.61 \mathrm{~mm}, 53.33 \%$ to $55.42 \%, 112.16$ to $125.01 \mathrm{~mm}^{2}$ and 41 to $57^{\circ}$ as the moisture content increased from $4 \%$ to $22 \%$ w.b., respectively. The thousand grain weight (TGW) increased from 80.3 to $96.8 \mathrm{~g}$ whereas the bulk density decreased from 410 to $380 \mathrm{kgm}^{-3}$ and the true density from 740 to $980 \mathrm{~kg} \mathrm{~m}^{-3}$ with an increase in the moisture content range of 4-22\% w.b.The data of sunflower seeds showed that the porosity ranged from 44.59 to $61.22 \%$. The static coefficient of friction of sunflower seeds increased linearly against different surfaces of structural materials, namely, plastic (0.29-0.55), plywood (0.36-0.53), and galvanized iron (0.36-0.55) and the static angle of repose increased from $41^{\circ}$ to $57^{\circ}$, respectively when the moisture content increased from $4 \%$ to $22 \%$ w.b.
\end{abstract}

Keywords: Sunflower, Physical properties, Moisture content, SHF8190 variety

\section{Introduction}

Among the most important crops which considered by Iran Agricultural Division are oilseeds, For instance sunflower oil seeds with cultivated area of about 10 thousands hectares in Golestan province, Iran as well as average yield of $1000 \mathrm{kgh}^{-1}$ (Ghodsevali and Vafaei, 2008). In order to design equipment for handling, conveying, separation, drying, aeration, storing and processing of sunflower seeds, it is essential to determine their physical properties as a function of moisture content. The properties of different types of grains and seeds have been determined by other researchers such as Dutta et al. (1988) for gram seed; Amin et al. (2004) and carman (1996) for lentil seed; Ougt (1998) for white Lupin; Baryeh (2002) for millet; Cetin (2007) for barbunia bean; Ogunjimi et al. (2002) for locust bean seed and Coskun et al. (2006) for sweet corn seed. Bulk density, true density and porosity can be useful in sizing grain hoppers and storage facilities. They can affect the rate of heat and mass transfer of moisture during aeration and drying processes. Grain bed with low porosity will have greater resistance to water vapor escape during the drying process, which may lead to higher power to drive the aeration fans. The static coefficient of friction is used to determine the angle at which chutes must be positioned in order to achieve consistent flow of materials through the chute. Such information is useful in sizing motor requirements for grain transportation and handling (Ghasemi Varnamkhasti et al., 2007).

In this study, some physical properties of sunflower seed were determined, namely, size and shape, bulk and true densities, porosity, static coefficient of friction against the different material surfaces and angle of repose at various moisture contents in the range of $4-22 \%$ w.b. 


\section{Notations}

\begin{tabular}{|c|c|}
\hline $\mathrm{L}$, length, $\mathrm{mm}$ & TGW, thousand grain weight, $g$ \\
\hline W, width, mm & $\theta_{\mathrm{s}}$, static angle of repose, deg \\
\hline $\mathrm{T}$, thickness, mm & $\varepsilon$, porosity, $\%$ \\
\hline $\mathrm{S}$, surface area, $\mathrm{mm}^{2}$ & $\mathrm{D}_{\mathrm{g}}$, geometric mean diameter, $\mathrm{mm}$ \\
\hline $\mathrm{R}^{2}$, correlation determination & $\mathrm{D}_{\mathrm{p}}$, equivalent diameter, $\mathrm{mm}$ \\
\hline $\mathrm{R}_{\mathrm{a}}$, aspect ratio & $\mathrm{D}_{\mathrm{a}}$, arithmetic diameter, $\mathrm{mm}$ \\
\hline M, moisture content, $\%$ & $\mathrm{~V}$, volume, $\mathrm{mm}^{3}$ \\
\hline $\mathrm{M}_{\mathrm{i}}$, initial moisture content, $\%$ & $\mathrm{~S}_{\mathrm{p}}$, sphericity, \% \\
\hline $\mathrm{M}_{\mathrm{f}}$, final moisture content, $\%$ & $\rho_{\mathrm{b}}$, bulk density, $\mathrm{kgm}^{-3}$ \\
\hline $\mathrm{W}_{\mathrm{t}}$, total weight of sample, $\mathrm{g}$ & $\rho_{\mathrm{t}}$, true density, $\mathrm{kgm}^{-3}$ \\
\hline $\mathrm{Q}$, weight of required water, $\mathrm{g}$ & \\
\hline
\end{tabular}

\section{Materials and Methods}

Sunflower (SHF8190) seeds were used for all the experiments in this study (Figure 1). The crop was collected from Plant and Seed Institute in Karaj. The initial moisture content of seeds was determined by oven method (Tabatabaeefar, 2003) and the rewetting formula (Equation 1) was used for obtaining the desired moisture level as 12,16 , and $22 \%$ w.b. then they were placed in refrigerator to allow the moisture be absorbed by samples.

$Q=\frac{W_{t}\left(M_{f}-M_{i}\right)}{\left(100-M_{f}\right)}$

\subsection{Size and shape}

For determining length, width and thickness of about 40 randomly selected seeds of each sample, a digital caliper was used. The geometric mean, $D_{g}$, equivalent, $D_{p}$, and arithmetic diameter, $D_{a}$, in mm was calculated by using these equations (Mohsenin, 1970):

$\mathrm{D}_{\mathrm{g}}=(L D T)^{\frac{1}{3}}$

$\mathrm{D}_{\mathrm{p}}=\left[L \frac{(\boldsymbol{W}+\boldsymbol{T})^{2}}{4}\right]^{\frac{1}{3}}$

$\mathrm{D}_{\mathrm{a}}=\frac{(L+W+T)}{3}$

For obtaining sphericity $\left(\mathrm{S}_{\mathrm{p}}\right)$, the ratio of the surface area of the sphere having the same volume as that of seed to the surface area of grain was determined using the following formula (Mohsenin, 1970):

$\mathrm{S}_{\mathrm{p}}=\frac{(L D T)^{\frac{1}{3}}}{L}$

Jain and Bal (1997) used following formulas for obtaining grain volume, $\mathrm{V}$ and surface area, $\mathrm{S}$ :

$\mathrm{V}=0.25\left[\left(\frac{\pi}{6}\right) \mathrm{L}(W+T)^{2}\right]$

$\mathrm{S}=\frac{\pi B L^{2}}{(2 L-B)}$

where:

$\mathrm{B}=\sqrt{W T}$

Omobuwajo et al. (1999) calculated aspect ratio $\left(\mathrm{R}_{\mathrm{a}}\right)$ by:

$\mathrm{R}_{\mathrm{a}}=\frac{W}{L}$ 


\subsection{Thousand grain weight}

By counting 100 seeds and weighing them in an electronic balance to an accuracy of $0.001 \mathrm{~g}$ and then multiplied by 10 to give mass of 1000 grains, thousand grain weight (TGW) was measured.

\subsection{Bulk and true densities and porosity}

A container was used to determine bulk density which is the ratio of the mass sample of seeds to its total volume by filling to a constant height, striking the top level and then weighing the container (Deshpande et al., 1993). For measuring true density which is a ratio of mass sample of seeds to its pure volume, the toluene displacement method was used (Mohsenin, 1970). The following formula was used for measuring the porosity which is the ratio of free space between seeds to total of bulk grains:

$\varepsilon=\frac{\rho \mathrm{t}-\mathrm{\rho b}}{\mathrm{\rho b}} \times 100$

\subsection{Static Coefficient of Friction}

By the apparatus which is shown in Figure 2, the static coefficient of friction was determined with respect to different surfaces: plywood, plastic and galvanized iron. It was done by using a small rectangular frame which is open at both ends filled with the seeds at the desired moisture content and placed on adjustable titling surface in a way that the metal cylinder did not contacts the surface. Then the surface was raised gradually until the filled cylinder just started to slide down (Razavi and Milani, 2006).

\subsection{Static Angle of Repose}

The apparatus which is shown in Figure 3 was used for measuring the static angle of repose. It consists of a plywood box of 140-160-35 mm and two plates (fixed and adjustable). After filling the box with the sample, the adjustable plate was inclined slowly allowing the seeds to follow and assume a natural slope (Tabatabeefar, 2003).

\section{Results and discussion}

\subsection{Size and shape}

In Table 1, a summary of the dimensions of SHF8190 sunflower cultivar is shown. All dimensions have similar tendency and first decreased with the increase in moisture content from 4 to $12 \%$, then $\mathrm{L}$ started to increase in the range of $12-22 \%$ but $\mathrm{W}$ and $\mathrm{T}$ didn't have this behavior and again decreased with an increase in moisture content from $16 \%$ to $22 \%$ w.b. The sphericity, volume, surface area, aspect ratio, geometric mean diameter, equivalent diameter and arithmetic diameter had the same behavior. These behaviors may be due to the lowness of sample numbers or the complexity of moisture content impact on seeds. The increasing trend in axial dimensions, with seed in moisture content was due to the filling of capillaries and voids upon absorption of moisture and subsequent swelling (Table 1).

\subsection{Thousand grain weight}

As the moisture content increased from 4\% - 22\% w.b., thousand grain weight (TGW) increased considerably from 80.3 to $96.8 \mathrm{~g}$ (Fig. 4). Linear relationship for one thousand grain weight with moisture content, M, was determined as follows:

$\mathrm{TGW}=0.952 M+75.18 \quad \mathrm{R}^{2}=0.930$

Altuntas and Yildiz (2007) observed a linear increase for the thousand grain weight of faba bean from 1140.15 to $1332.67 \mathrm{~g}$ when the moisture content increased from $9.89 \%$ to $25.08 \%$ d.b.

\subsection{Bulk and true densities and porosity}

The values of the bulk density for different moisture levels varied from 710 to $649 \mathrm{kgm}^{-3}$ (Figure 5). The following relationship was obtained for the bulk density of seed with moisture content:

$\rho_{b}=-0.001 M+0.412$

$$
\mathrm{R}^{2}=0.830
$$

Gupta and Das (1997) reported a similar decreasing trend in bulk density for sunflower seed but Parde et al. (2003) found that the standard bulk density of Koto buckwheat increased significantly from 603.90 to 612.90 $\mathrm{kgm}^{-3}$ with an increase in moisture content from 14.8 to $15.8 \%$.

True density varied from 1250 to $1325 \mathrm{kgm}^{-3}$ when the moisture level increased from $4 \%-22 \%$ w.b. (Fig. 6). True density and the moisture content of seed can be correlated as follows:

$\rho_{t}=1.739 M^{2}-29.19 M+810.3 \quad \mathrm{R}^{2}=0.710$

With increase in moisture content from $4 \%-22 \%$ w.b., the porosity of sunflower seeds increased linearly from 
$43.2 \%$ to $51 \%$ (Figure 7 ). The following equation represents the relationship between porosity and moisture content:

$\varepsilon=0.104 M^{2}-1.594 M+48.01 \quad \mathrm{R}^{2}=0.700$

Gupta and Das (1997) found linear relationship between porosity and true density with moisture content of sunflower seeds. Baumler et al., 2004, reported an increase in porosity against moisture content and evaluated the relationship between porosity and moisture content for safflower seed as:

$\mathrm{e}=39.53+0.34 M \quad \mathrm{R}^{2}=0.930$

\subsection{Static coefficient of friction}

For determining the static coefficient of friction of sunflower seed, three surfaces (plastic, plywood and galvanized iron) were selected. The results are presented in Figure 8. From this Figure, it can be seen that the static coefficient of friction increased with an increase in moisture content for all the surfaces. The increased adhesion between the seeds and the material surfaces at higher moisture values may be the reason of this increment. For plastic, plywood and galvanized iron increases of $81.25 \%, 46.11 \%$ and $52.32 \%$ were recorded when the moisture content increased from $4 \%$ to $22 \%$ w.b. The galvanized iron had the highest static coefficient of friction. Following equations show the relationships between static coefficient of friction and moisture content on plastic, plywood and galvanized iron:

$$
\begin{array}{ll}
\varphi \text { plyw }=0.009 M+0.337 & \mathrm{R}^{2}=0.965 \\
\varphi \text { galv }=0.010 M+0.338 & \mathrm{R}^{2}=0.926 \\
\varphi \text { plas }=0.015 M+0.229 & \mathrm{R}^{2}=0.966
\end{array}
$$

Gupta and Das (1997) represented a linear increase in friction against mild steel and galvanized iron for sunflower seeds. Sahoo and Srivastava (2002) found similar results for okra. Parde et al. (2003) reported that for the Koto buckwheat cultivar the friction coefficient against plywood, galvanized steel and concrete surfaces increased significantly from 0.26 to $0.31,0.25$ to 0.29 and 0.38 to 0.43 respectively, with increase in moisture content from $14.8 \%$ to $17.9 \%$.

\subsection{Angle of repose}

Angle of repose were found to increase significantly from $41^{\circ}$ to $58^{\circ}$ in the moisture range of 4 to $22 \%$ w.b. (Figure 9). The following relationship was obtained with the static angle of repose for sunflower with its moisture content.

$\theta s t=0.897 M+38.63 \quad \mathrm{R}^{2}=0.963$

Gupta and Das (1997) reported that the porosity of sunflower seeds and kernels increase linearly from 34.3 to $43.3 \%$ and from 45.4 to $50.2 \%$, respectively when the moisture content changed from 4 to $20 \%$ d.b. Parde et al., (2003) reported that the emptying angle of repose for Koto buckwheat cultivar remained constant at about $23.5^{\circ}$ from 14.8 to $15.8 \%$ of moisture content and then increased significantly, the filling angle of repose did not change significantly at 14.8 to $16.6 \%$ but increased significantly to $28.4^{\circ}$ at $17.9 \%$. For wheat, Tabatabeefar (2003) found that the values of dynamic angle of repose increased from $34.7^{\circ}$ to $45^{\circ}$ in the moisture range of 0 to $22 \%$ d.b.

\section{Conclusions}

For sunflower seeds, the conclusions in the moisture content range of $4 \%$ to $22 \%$ w.b. are as follows: The average length, width, thickness, geometric mean diameter, equivalent diameter, arithmetic diameter, sphericity, thousand grain weight, grain volume, porosity and surface area of sunflower seeds ranged from 12.14 to 12.57 $\mathrm{mm}, 5.79$ to $6.38 \mathrm{~mm}, 3.86$ to $4.09 \mathrm{~mm}, 6.47$ to $6.85 \mathrm{~mm}, 6.56$ to $6.97 \mathrm{~mm}, 7.27$ to $7.61 \mathrm{~mm}, 53.33 \%$ to $55.42 \%$, 80.3 to $96.8 \mathrm{~g}, 148.96$ to $177.81 \mathrm{~mm}^{3}, 36.89 \%$ to $61.22 \%$ and 112.16 to $125.01 \mathrm{~mm}^{2}$, respectively. Bulk density was found to decrease from 419.59 to $381.6 \mathrm{kgm}^{-3}$ but true density increased with increase in moisture content. The static coefficient of friction of sunflower seeds against different materials (plastic, galvanized iron and plywood) increased with increase in moisture content. The galvanized iron had the highest static coefficient of friction. Increase in moisture content resulted a linear increase in angle of repose from $41^{\circ}$ to $57^{\circ}$. From these results, it can be concluded that changes in moisture content of seed have a significant impact on physical properties of sunflower seed and it is important to determine physical properties of sunflower seeds at different moisture levels.

\section{References}

Altuntas, E., \& Yildiz, M. (2007). Effect of moisture content on some physical and mechanical properties of faba 
bean (Vicia faba L.) grains. Journal of Food Engineering 78, 174-183.

Amin, M. N., Hossain, M. A., \& Roy, K. C. (2004). Effects of moisture content on some physical properties of lentil seeds. Journal of Food Engineering, 65(1), 83-87.

Baumler, E., Cuniberti, A. Nolasco, S. M., \& Riccobene, I. C. (2006). Moisture dependent physical and compression properties of safflower seed. Journal of Food Engineering. 72: 134-140

Baryeh, E. A. (2002). Physical properties of millet. Journal of Food Engineering, 51:39-46.

Carman, K. (1996). Some physical properties of lentil seeds. Journal of Agricultural Engineering Research, 63(2), 87-92.

Cetin, M. (2007). Physical properties of barbunia bean (Phaseolus vulgaris L. cv. 'Barbunia') seed. Journal of Food Engineering, 80, 353-358.

Coskun, M. B., Yalcin, I., \& Ozarslan, C. (2006). Physical properties of sweet corn seed (Zea mays saccharata sturt). Journal of Food Engineering, 74, 523-528.

Deshpande, S.O., Bal, S. and Ojha. T.P. (1993). Physical properties of soybean. Journal of Agricultural Engineering Research 56: 89 - 98.

Dutta, S. K., Nema, V. K., \& Bhardwaj, R. K. (1988). Physical properties of gram. Journal of Agricultural Engineering Research, 39, 259-268.

Ghasemi Varnamkhasti, M., Mobli, H., Jafari, A., Rafiee, S., Heidary Soltanabadi, M., \& Kheiralipour, K. (2007). Some Engineering Properties of Paddy (var. Sazandegi). International Journal of Agricultural and Biology, 5: 763-766.

Ghodsevali, A., \& Vafaei, A. (2008). Studying of physical properties of sunflower in Golestan province. the fifth conference of agricultural machinery and mechanization, Mashad, Iran, 306.

Gupta, R. K., \& Das, S. K. (1997). Physical properties of sunflower seeds. Journal of Agricultural Engineering Research, 66: 1-8

Jain, R. K., \& Bal, S. (1997). Properties of pearl millet. Journal of Agricultural Engineering Research, 66: 85-91.

Mohsenin, N. N. (1970). Physical Properties of Plant and Animal Materials, 2nd ed. Gordon and Breach Science Publishers, New York.

Ogunjimi, L. A. O., Aviara, N. A., \& Aregbesola, O. A. (2002). Some engineering properties of locust bean seed. Journal of Food Engineering, 55(2), 95-99.

Omobuwajo. O.T., Akande, A.E. and Sann, A.L. (1999). Selected physical, mechanical and aerodynamic properties African Breadfruit (Treculia Africana) seeds. Journal of Food Engineering 40: 241-244.

Ougt, H. (1998). Some physical properties of white lupin. Journal of Agricultural Engineering Research, 69, 273-277.

Parde, S. R., Johal, A., Jayas, D. S., \& White, N. D. G. (2003). Physical properties of buckwheat cultivars. Canadian Bio-systems Engineering, Technical Note.

Razavi, S., \& Milani, E. (2006). Some physical properties of the watermelon seeds. African Journal of Agricultural Research, 13: 65-69.

Sahoo, P. K., \& Srivastava, A.P. (2002). Physical properties of okraseed. Bio-systems Engineering, 83: 441-448.

Tabatabeefar, A. (2003). Moisture-dependent physical properties of wheat. International Agrophysics, 17: 207-211. 
Table 1 . Some physical properties of Shf8190 variety considering moisture content.

\begin{tabular}{|c|c|c|c|c|}
\hline MC (\% w.b.) & 4 & 12 & 16 & 22 \\
\hline $\mathrm{L}(\mathrm{mm})$ & $12.24 \pm 1.57$ & $12.14 \pm 0.93$ & $12.38 \pm 1.46$ & $12.60 \pm 1.18$ \\
\hline $\mathrm{W}(\mathrm{mm})$ & $6.05 \pm 0.9$ & $5.79 \pm 0.69$ & $6.37 \pm 0.80$ & $6.05 \pm 0.865$ \\
\hline $\mathrm{T}(\mathrm{mm})$ & $4.04 \pm 0.72$ & $3.87 \pm 0.87$ & $4.09 \pm 0.15$ & $3.85 \pm 1.21$ \\
\hline $\mathrm{Dg}(\mathrm{mm})$ & $6.68 \pm 0.70$ & $6.47 \pm 0.61$ & $6.85 \pm 0.38$ & $6.64 \pm 0.58$ \\
\hline $\mathrm{Dp}(\mathrm{mm})$ & $6.77 \pm 0.65$ & $6.56 \pm 0.75$ & $6.97 \pm 0.42$ & $6.75 \pm 0.61$ \\
\hline $\mathrm{Da}(\mathrm{mm})$ & $7.44 \pm 0.77$ & $7.27 \pm 0.58$ & $7.61 \pm 0.39$ & $7.49 \pm 0.69$ \\
\hline $\mathrm{Sp}(\%)$ & $54.62 \pm 3.30$ & $53.33 \pm 3.75$ & $55.42 \pm 2.60$ & $52.82 \pm 1.68$ \\
\hline $\mathrm{S}\left(\mathrm{mm}^{2}\right)$ & $119.27 \pm 16.00$ & $112.16 \pm 12.49$ & $125.01 \pm 9.94$ & $118.09 \pm 11.24$ \\
\hline $\mathrm{V}\left(\mathrm{mm}^{3}\right)$ & $164.60 \pm 34.11$ & $148.96 \pm 24.41$ & $177.81 \pm 22.14$ & $162.22 \pm 24.95$ \\
\hline $\mathrm{Ra}(\%)$ & $49.48 \pm 4.54$ & $47.81 \pm 4.59$ & $51.57 \pm 3.31$ & $48.10 \pm 3.02$ \\
\hline
\end{tabular}

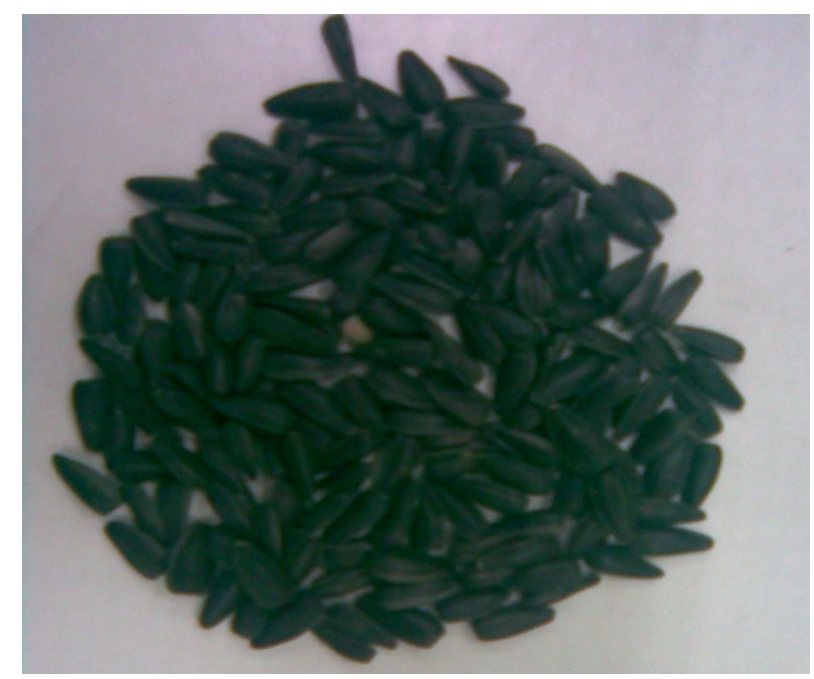

Figure 1. Sunflower Seeds

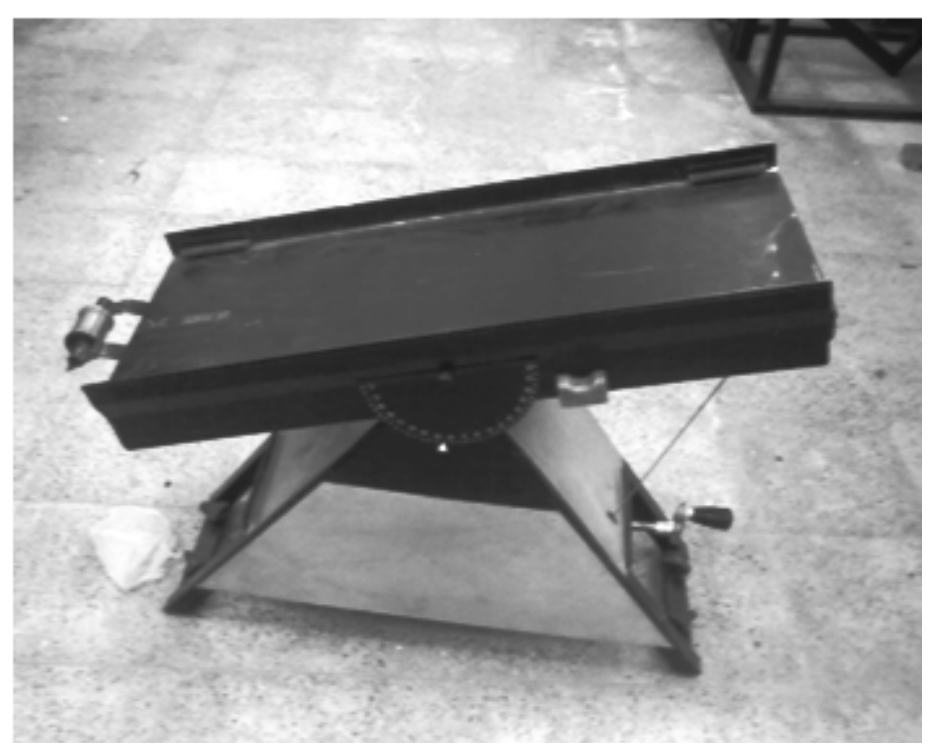

Figure 2. Apparatus to determine coefficient of static friction 


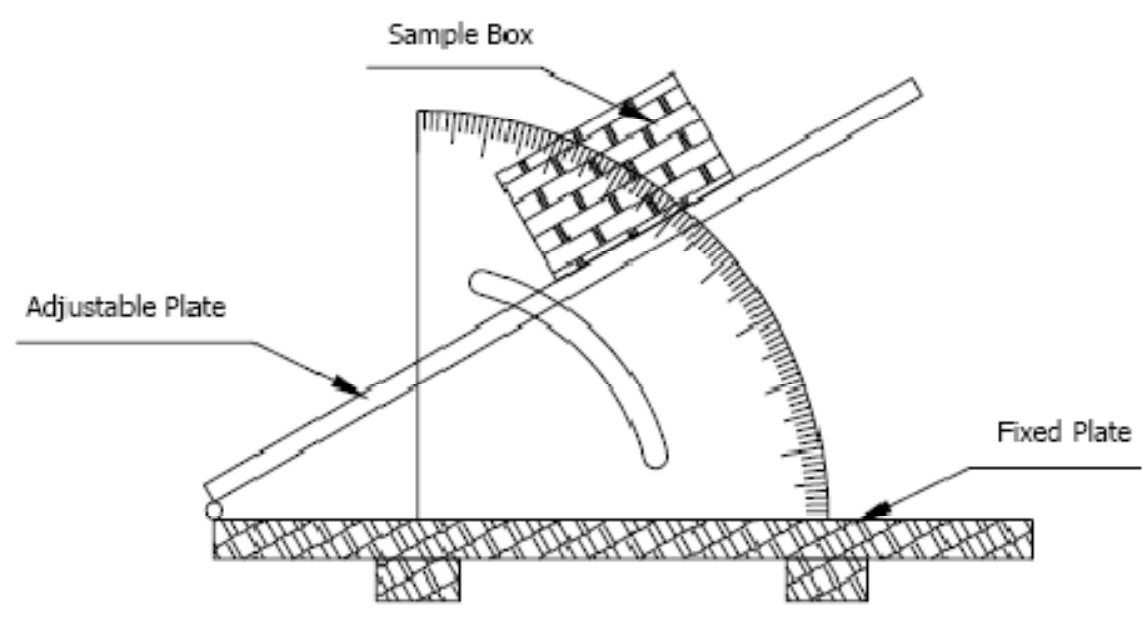

Figure 3. Empting angle of repose device

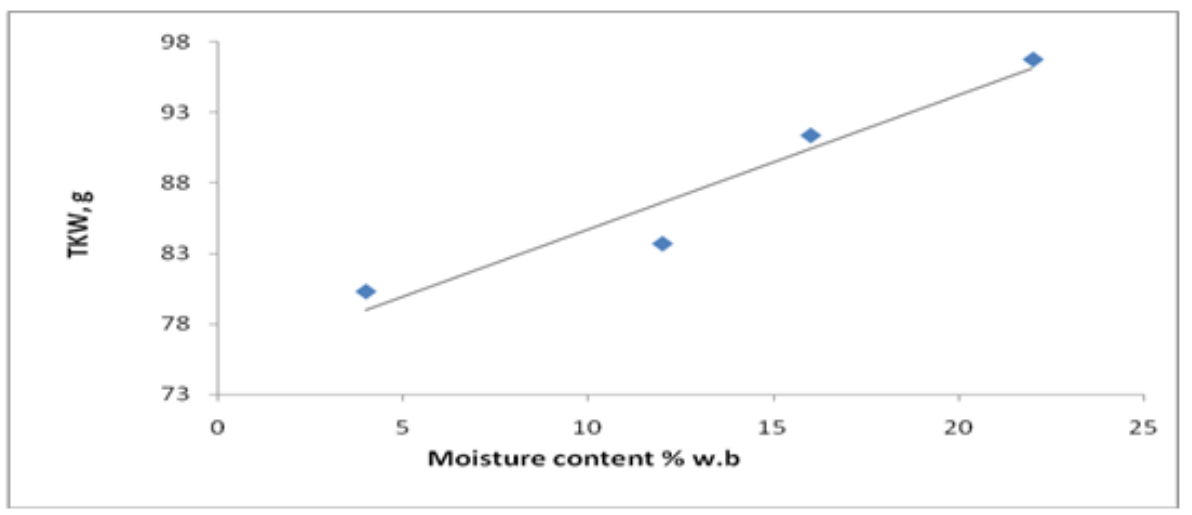

Figure 4. Effect of moisture content on thousand grain weight

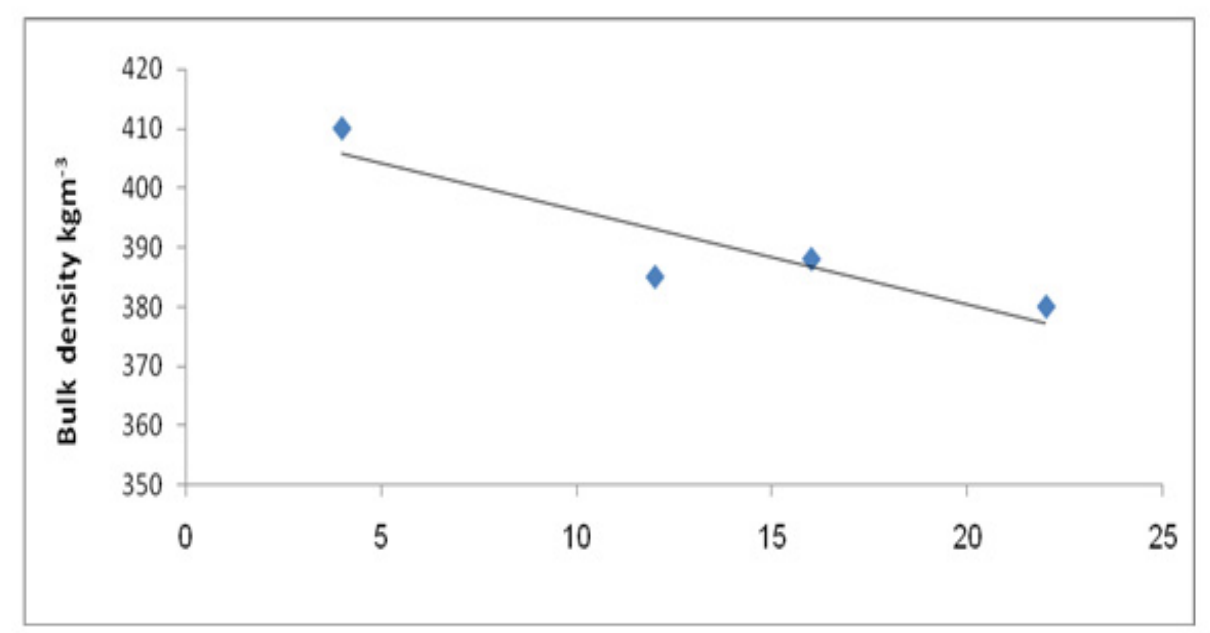

Figure 5. Effect of moisture content on bulk density 


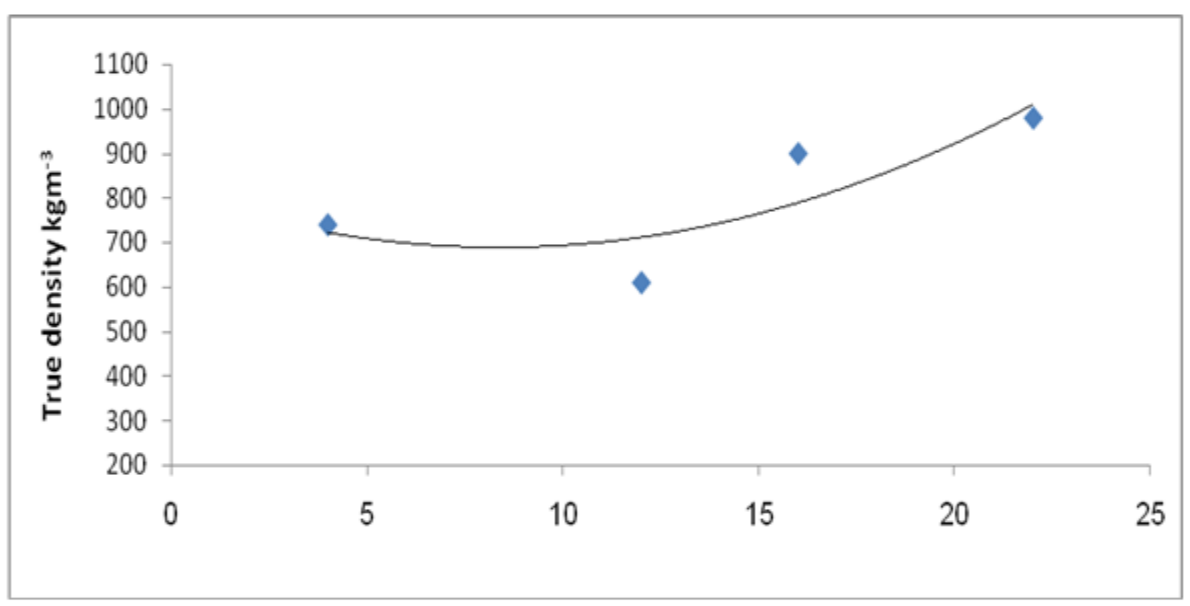

Figure 6. Effect of moisture content on true density

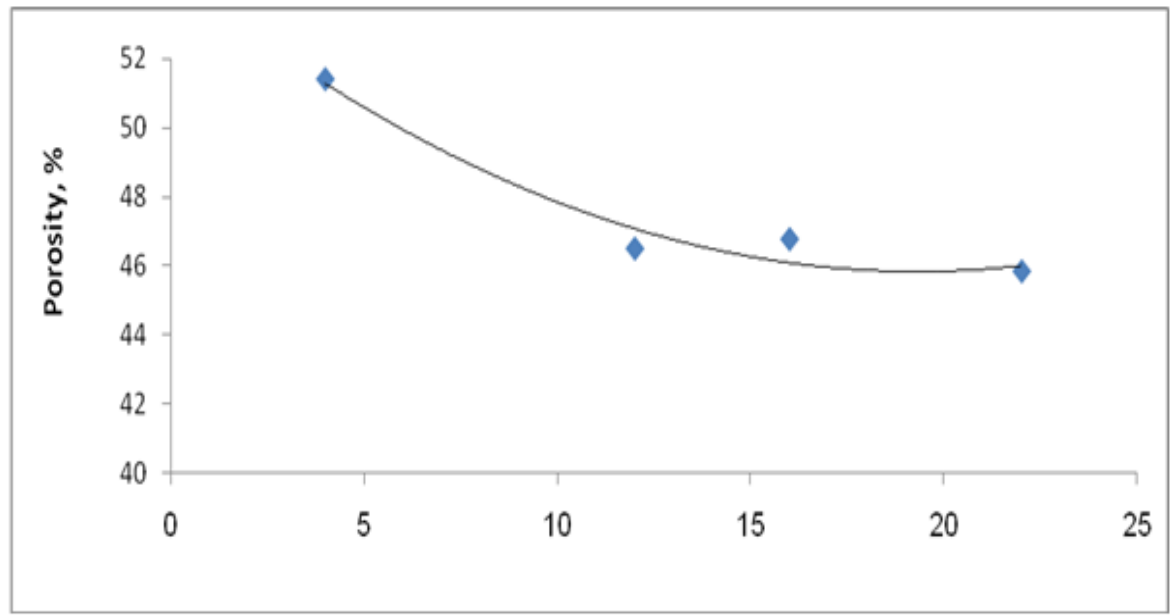

Figure 7. Effect of moisture content on porosity

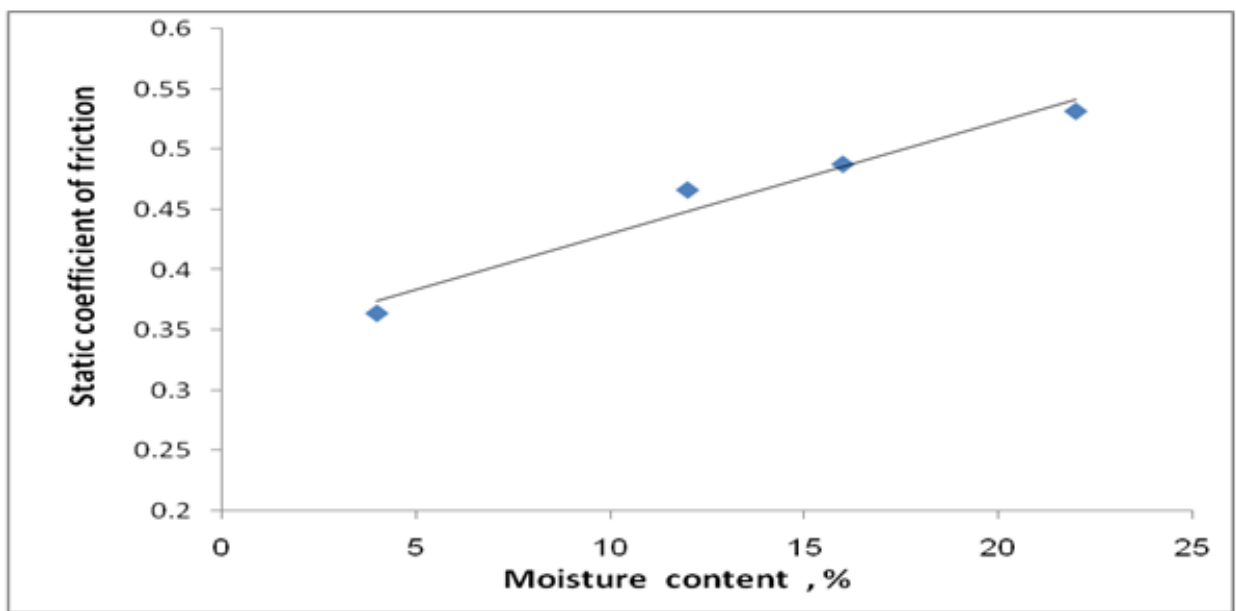



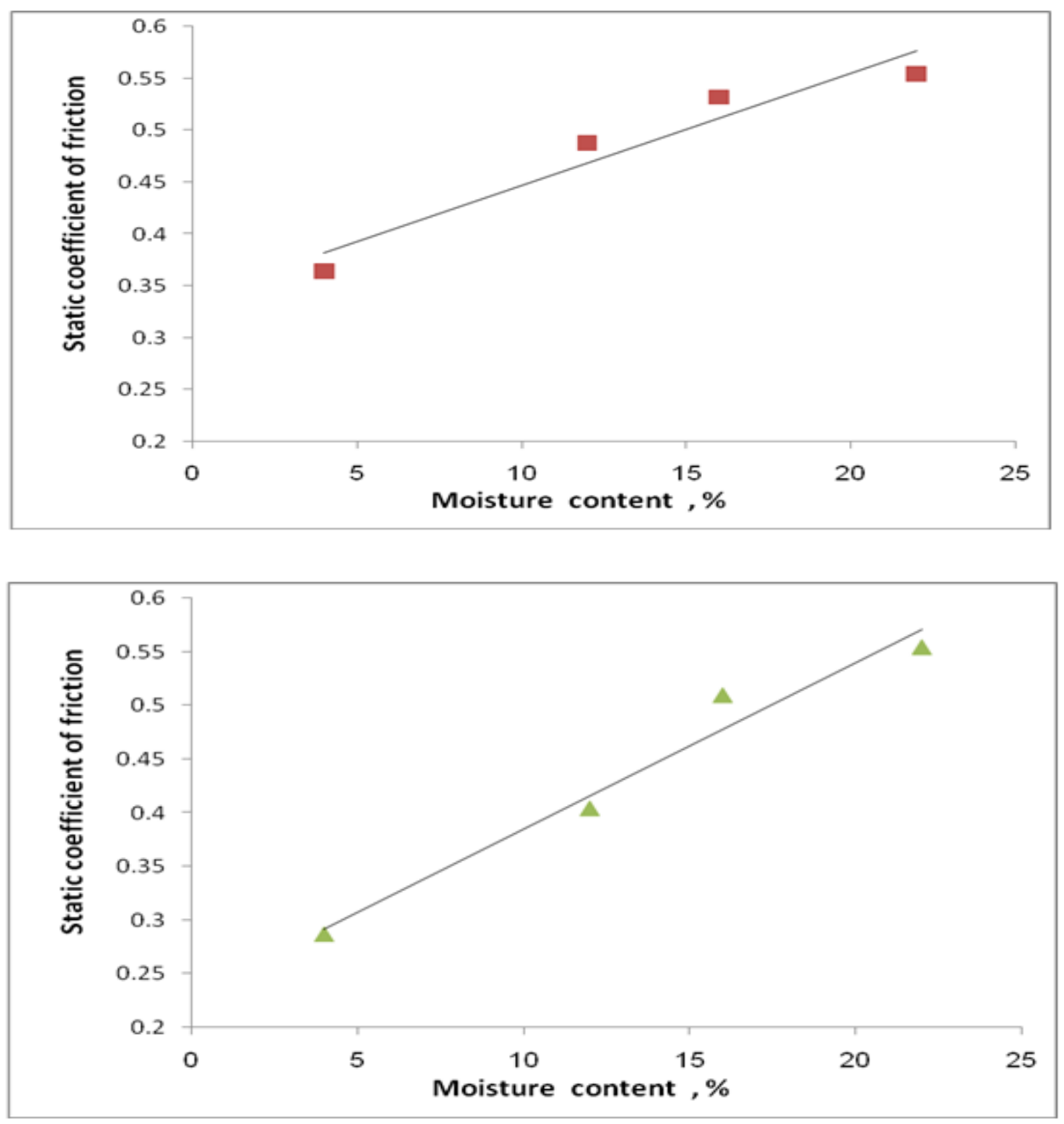

Figure 8. Effect of moisture content on static coefficient of friction: plastic $(\Delta)$; galvanized iron $(\square)$ and plywood $(\diamond)$.

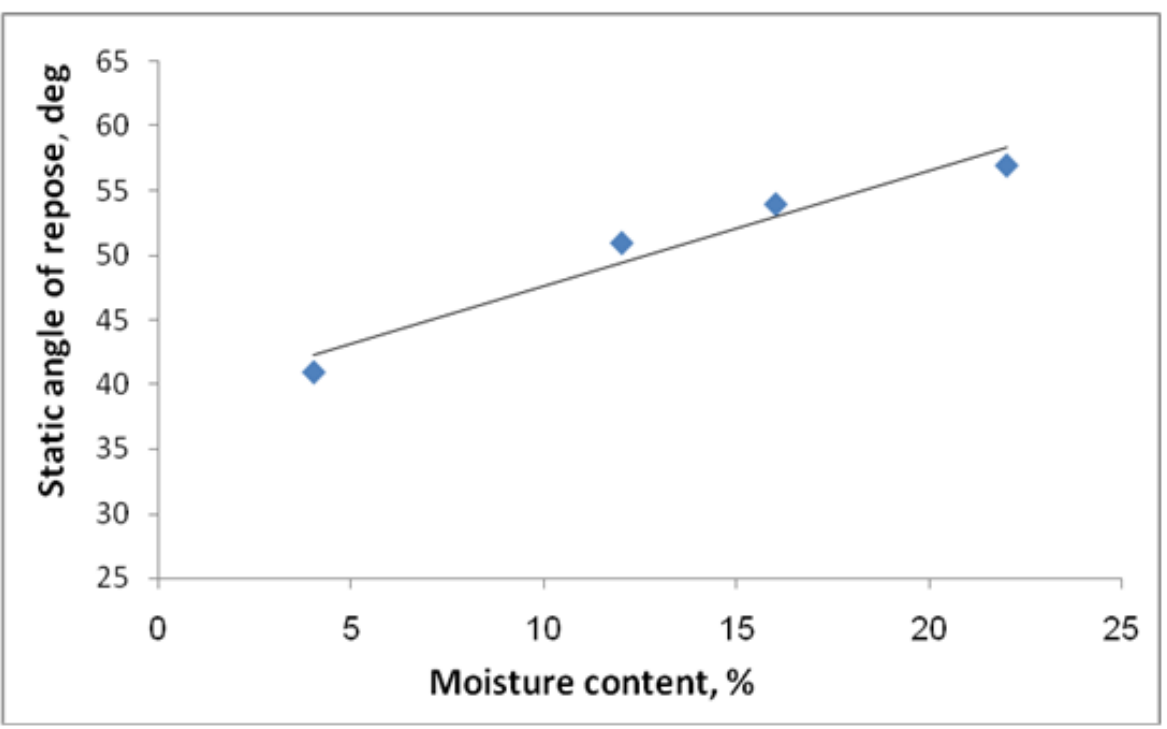

Figure 9. Effect of moisture content on static angle of repose 